\title{
Are Leaders Alike all over? A Cross-Cultural Study to Assess the Impact of Communication and Personality on Leadership Style
}

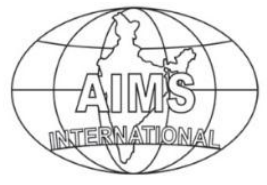

DOI: $10.26573 / 2017.11 .3 .4$

Volume 11, Number 3

September 2017, pp. 207-221

\author{
Amit Shah \\ Michael Monahan \\ Frostburg State University \\ (ashah@frostburg.edu) \\ (mmonahan@frostburg.edu)
}

Leadership is needed for practically every human endeavor. While there are arguably as many types of leadership as nations on the globe the researchers sought to determine if there were commonalities in leadership styles among university students from two disparate countries who at first glance are separated by distance and culture: India and Sweden. Using the Bolman and Deal Four Frame Model leadership style was determined by country, gender, personality type and level of communication skills. Over 800 usable responses were obtained, and statistically significant differences were found. Implications for practice are also discussed.

Keywords: Bolman and Deal, Leadership Styles, India, Sweden, University Students

\section{Introduction}

At its most basic level leadership is influencing others to achieve organizational goals. While there are a myriad of leadership instruments the researchers received permission to use the Bolman and Deal Leadership Orientations Self instrument. By using an instrument with proven reliability, the respondents would respond to the same questions, thus enabling different populations to be readily compared.

To influence or advance change with ease and efficiency, communication is needed. It is the often the lynchpin used to motivate and direct followers toward these new objectives. In addition, perhaps the personality orientation; Introvert or Extrovert may also be a factor. The researchers compared the respondents selfreported personality type to analyze those who see themselves as reserved and quiet and those who are outgoing and boisterous were compared.

The researchers began by questioning the well-known saying "people are alike all over" to ascertain if leadership style was consistent across very disparate cultures using the same survey instrument which has high reliability. Two countries, which superficially have nothing in common: India and Sweden, were the focus of this study. One is a south eastern Asian giant with over 1.2 billion people while the other is a small Nordic county with only 30 million people.

While much study has been done on gender, ethnicity, marital status, and grade level, the researchers used gender, but also investigated personality style; Introvert or Extrovert, and level of communication proficiency. The use of communication as a 
factor is critical since articulating the vision and influencing others is done through unambiguous communication. Further, while there are indeed quiet leaders, it appears most leaders possess Extrovert tendencies.

\section{Hypothesis Formulation and Literature Review}

\subsection{Research Hypothesis}

H1: There is no difference in the leadership styles, leadership frames and strongest and weakest frames of university students from India and Sweden

H2: There is no difference in the leadership styles of university students from India and Sweden on the basis of gender, personality type and communication skills.

H3: There is no difference in the leadership frames of university students from India and Sweden on the basis of gender, personality type and communication skills.

H4: There is no difference in the strongest and weakest frames of university students from India and Sweden on the basis of gender, personality type and communication skills.

\subsection{Bolman and Deal Model}

Researchers Lee Bolman and Terrance Deal were not content with the prevailing juxtaposition of task and relationship to explain leadership developed their own theory- the Four Frame Model (Bolman and Deal 1991, 1997). Their theory consists of both styles and frames where the styles can be compared to the "parent" and the frames the "children" under the styles. Participants can have a Single style, a Paired style, a Multi-style ( 3 or 4 styles) or No style. The No style is not the absence of leadership style, but signifies the participants' responses did not reach the level for style and frame usage.

The frames have four vital components: Structural, Human Resources, Political, and Symbolic. The Structural and Human Resources frames are related to managerial efficiency. The first frame is the Structural frame which stresses effectiveness and goals. An effective organization will have clear goals; individuals will have specific roles, with different activities functioning through guidelines, rules, and a chain of command. Leaders that reflect this frame focus on the main idea or task, value data, have clear direction, are accountable, and believe others are accountable, and solve problems using a set of rules If a problem occurs, the leader will change their path to comply with a new set of rules (Bolman \& Deal, 1991). The second frame is Human Resources which focuses its attention on the needs of the people working in the organization. This frame posits if a company or organization meets the basic needs of the individual, then those working at that company will work better than those that do not. Leaders who value this frame believe relationships and feelings are of high value as they aid and empower their workers. If problems occur, the leader will focus on interpersonal solutions to fix the problem (Bolman \& Deal, 1991). The third frame is Political where organizations are viewed as a place to compete for limited resources. Leaders who employ this frame value practicality and negotiate as they network and build coalitions to strengthen their company (Bolman \& Deal, 1991).The fourth and final frame is the Symbolic frame. This frame views ideas and facts as interpretative instead of objective and they promote symbols which instills a sense of identity and promise. Those employing this strategy are attuned to "rituals, stories, and other symbolic forms" (Bolman \& Deal, 1991). 
Bolman and Deal developed the four different frames as a vehicle where users could arrive at solutions apart from a single perspective (Bolman \& Deal, 1984). The four frames represent the ways in which leaders can view organizational situations and manage them effectively. Those leaders who can utilize all four frames are thought to be the most effective leader (Thompson, 2000). Bolman and Deal (1991) assert that our modern world is increasingly multifaceted and tempestuous and therefore requires greater cognitive complexity. Therefore, effective managers who understand and utilize multiple frames may be more effective.

Bolman and Deal (1991) conducted studies to determine the number of frames leaders utilized and identified which frames were employed by surveying three different samples of educational administrators. The first sample consisted of 145 higher education administrators, from colleges and universities throughout the United States with positions ranging from department chairs to institutional presidents. The second sample consisted of 15 superintendents in Minnesota and 48 principals in Florida, while the third sample had encompassed more than 220 administrators, mostly school principals participating in leadership workshops in Singapore. Results revealed all three samples rarely utilized more than two frames and rarely did anyone use all four frames (Bolman \& Deal, 1991). All three samples showed the majority, (over 60\%) of respondents utilized the Structural frame verifying that policies and procedures were consistent characteristics for leaders everywhere. The Human Resources frame was minimally employed by the higher education administrators. Similarly, low usage was found with the Symbolic frame in all three samples. Conversely, the Political frame was employed at a rate higher in education administrators than the other two samples. Consequently, it was found leaders in more complex firms and organizations need to understand and consider using the other frames to which can enable them to become more effective leaders. Further, it was concluded that managerial effectiveness was linked primarily to structure and rationality while and leadership effectiveness was primarily linked to symbols and politics.

\subsection{India}

Sinha, (1984) asserts the effectiveness of a working leadership style is dependent on task characteristics and the context of the leader-employee relationship. However, in India, task characteristics appear to be less important than in other countries due to their cultural preference to view work as a relationship. Indian workers appear to prefera personalized relationship with their employers instead of a contractual relationship. Bloom, Genakos, Sadun, and Van Reenen (2012) found that Chinese, Indian, and Brazilian manufacturing firms tended to be less well managed compared to manufacturing firms in America, Germany, and Japan. One possible explanation may be that India and China tend to utilize an autocratic style of leadership. Further, the concept of moral leadership as illustrated though the Indian scriptures as examples of visionary leadership combined Indian thought with Western ideas to create moral leadership, or values driven leaders (Sapre \& Ranade, 2001).

CEOs in India also consider their nation's welfare before making important business decisions (Gutierrez, Spencer, \& Zhu, 2012). For example, they view an ideal boss as someone who would be a compassionate source for workers who they can turn to for help. The workers accept the superior's higher status and respects and obey him, since he supports the workers and accommodates their work, personal, and 
social needs (Sinha, 1980). In a study of 400 employees from ten manufacturing firms in India Dasgupta, Suar, and Singh (2013) found the assertive style of communication lends maximum support to employees. Perceived supervisory support at the workplace enhances employees' satisfaction with their communication with supervisors and their organization-based self-esteem. In addition, satisfaction with communication fosters a strong emotional bond with organizations which reduces employees' absenteeism.

Sinha, (1980) created a more cultural-specific leadership model, called the nurturant-task leadership model. In this model a leader should be a nurturant, shows affection and cares for workers, and is committed to their growth and development. This model states that to be an ideal leader, one must be task oriented as well as nurturant (Palrecha, Spangler, \& Yammarino, 2012). Nurturant Task Leadership allows managers to enlist the participation and cooperation of followers by appealing not just rationally, but emotionally as well (Gonsalves \& Dhende, 2015). However, the leader makes his nurturance dependent on the workers task accomplishment (Sinha 1984). The leader structures his interactions with the workers roles and interactions, so the workers understand the goals and the structure that is expected of them. The leader then drives the employees to work harder to maintain a higher level of productivity. Consequently, when the employees meet these expectations, they are rewarded and reinforced with nurturance which. Enables both the leader and workers to grow in understanding, interdependence, warmth, and higher productivity.

Transformation leadership is one of the most accepted and extensively studied leadership styles. Biwas (2011) found that Indian companies who used a transformational style of leadership were positively correlated with employee job satisfaction. In addition, Doh et al (2011) contend strong leadership which focused on the employees' human needs was effective in decreasing employee turnover.

Business today (2010) compared Indian and American companies and found American companies placed a greater emphasis on external aspects, such as regulatory and board concerns. Conversely, companies in India placed a greater emphasis on the company's structure and culture, as well as setting strategies. Paternalistic leadership, which combines kindness and compassion with authority, is strong in India and has been positively correlated to job satisfaction. However, in America, no significant correlation was found (Pellegrini, Scandura, \& Jayaraman, 2010).

Leadership may be viewed to achieve specific goals through the influence of others' attitudes and behaviors. In India, Desale (2008) asserts an effective leader one must be transparent and make employees' cognizant of their potential and value. One study discovered that among executives, missionary leadership is the preferred style and the deserter style was the least favored. Leaders who use a deserter style were passive while those who use a missionary style placed great value on harmony (Limbare, 2012). Nandamuri \& Rao (2011) found $75 \%$ of leaders in academia preferred democratic leadership. However, Indian manufacturing executives were found to follow a rational leadership style as Transformational (TFM) leaders were rational, while the transactional (TSL) leaders were observed to be rational and dependent (Verma et al., 2015).

Sharma, Sun, and Kannan (2012) studied the leadership of school principals in Malaysia, China, and India. However, no differences were found between gender, tenure, or nationality and the principal's rating. This finding may suggest principals 
who have effective leadership qualities were viewed positively by teachers regardless of nationality, gender, or tenure. In addition, a study of 57 leaders by 472 subordinates Thompson (2000) found both female and male educational leaders were perceived to be equally effective in their respective organizations. Further, Indian principals who practiced strong interpersonal skills were perceived more favorably by teachers, students and parents (Khetarpal \& Srivastava, 2000).

McFadden et al. (2013) studied community college personnel and found the structural and human resource frames were the most utilized. Sudha, Shahnawaz, \& Far hat, (2016) studied ninety full-time employees in higher education found collective efficacy as a factor in teambuilding. In a study of higher education administrators in India, Rao (2013) found soft leaders, who are people oriented, rather than task oriented leaders had more success.

Monahan et al. (2015) found over half of the Indian students favored style was the "No Style." Again, this finding does not infer these students did not have a preferred style, but their ranking of the survey questions did not reach the level needed to register as usage. Perhaps this may be due to the Indian students being overly conservative in assessing their abilities. However, since India's societal value system revolves around the familial unit, which is the Human Resources, explains why this was the most employed frame. Conversely, the Political frame whose tenants are power, conflict, and influencing others was the least utilized thereby creating is an inverse relationship between the favored use of Human Resources and the lack of Political frame usage in India.

Sczesny et al. (2004) studied Management students from Australia, Germany and India and found an intercultural shared view of a female-specific leadership competence according to which women possess a higher person orientation than men. The self-descriptions of the female and male management students regarding person-and task-oriented traits were found to be very similar.

Lenka \& Tiwari (2016) asssert resonant leaders motivate their subordinates by being compassionate toward them, showing an overall positive mood, and for achieving sustainable triple "P" bottom line. However, India is a secular country that emphasizes spiritual beliefs as well as socio-cultural and religious values. Consequently, Indian managers generally adopt these values in their early socialization process by following traditional epics and religious scriptures. They spread positive emotions among their subordinates and raise their level of consciousness by exhibiting altruistic values. Therefore, altruism could be considered as an additional dimension of resonant leadership style of Indian managers for downsized firms.

Finally, Scandura, \& Jayaraman, (2010) studied 207 employees in India and found a strong correlation with respect to paternalistic leadership, which had a significant positive effect on job satisfaction (Pellegrini, 2010).

\subsection{Sweden}

Bass (1990) asserts the type of leadership pursued and the level of success was contingent on the congruence between cultural values and the leadership processes. To this end Lawrence and Spybey (1986) depicted Swedish decision-making as correspondingly participative between the leader and the employee. Further, it was customary for a Swedish manager to consult with their employees as Swedish leaders have a strong need to achieve agreement, to make decisions through 
democratic processes and for cooperation from all (Bjerke, 1999). Leaders portrayed as change-oriented, (Czarniawska-Joerges, 1993) adopted a strong focus on interpersonal relations so to keep their employees and co-workers integrated through enthusiasm (Trompenaars, 1995).

In a massive study of over 11,000 managers from 50 nations Hampden-Turner and Trompenaars (1993) and found that Swedish management embodied "social individualism", which referes to their individualism being strongly rooted in a collectivistic value-system (Holmberg \& Akerblom, 1998). Further, Swedish leaders tend to have a concern for doing what is dubbed decent and correct by the community (Smith, Anderson, Ekelund, Graversen, \& Ropo, 2003). Similarly, the "Swedish style" of leadership appears to work well and is referred to as the Nordic/Scandinavian management (Grenness, 2003; Sjoborg, 1986).

Likewise, in another substantial study of 7,000 managers from 47 different nations, Smith et al. (2003) developed a Nordic style profile which was reflected in respondents from Denmark, Norway, Finland and Iceland. This profile consisted of a strong reliance on formal rules and common beliefs which are viewed communally as correct. Further, the commitment to a particular goal is more important than relationships amongst members. Perhaps this is why management teams in Swedish companies are involved in problem-solving activities, discussing solutions via engagement and participation among the members (Edstrom \& Jonsson, 1998; Jonsson, 1995).

The Swedish style leadership style contains the factors of conflict aversion, participative decision-making, formality, change-orientation and a strong focus on interrelations (Holmberg \& Akerblom, 2006).Further, these researchers found charismatic/value-based and team-oriented leadership were universal qualities. However, characteristics like participative and autonomous leader characteristics were more culture-specific qualities. This finding supports the results founded by Zander and Romani (2004), and Gerstner and Day (1994) who assert national culture has a greater influence than education, age or gender.

The foundational Ohio State University Leadership Studies recognized consideration and initiating structure as the two behavioral factors in leadership (Fleishman \& Harris, 1962). However, in addition to this established dichotomy, a third component is prevalent in Swedish leaders, a change-centered leadership style (Ekvall \& Arvonen, 1991). This style portrays a leader who creates visions, makes quick decisions, encourages cooperation and accepts innovative ideas. The leader is not overcautious, and they do not stress that plans must be followed. Swedish principals were studied by Hansson and Andersen in 2007 study and found they predominantly used the leadership style of change-development. Bogler (2001) found teachers report greater satisfaction at their job when the principal shares information and has an open book policy and open communication with the teachers. In many ways this is similar to the change-development style (Hansson \& Andersen, 2007). Previous research completed by Andersen (2005), found principals scored relatively high on the change-development style and low on the relationship style. Andersen (2005) and Hansson and Andersen (2001) also found that managers in other businesses usually score more than $60 \%$ on relation-oriented style and less than $30 \%$ on the change-development style. Scandinavian management style is usually seen as relationship oriented (Hansson \& Andersen, 2007). Three different samples were drawn from people taking courses at staff training centers in Sweden, Finland, 
and U.S. and found the same pattern of leadership styles being used but three factors appeared in all sample: employee-centeredness, production-centeredness, and promoting change.

Lindberg and Vanyushyn (2013) examined principals' views of the importance of school-based management and instructional leadership tasks and found school-based management and instructional leadership work in Sweden, just like in other AngloSaxon countries.

When examining data, Ekvall and Arvonen (1991, 1994) found several hundred managers in Sweden, Finland, and United States possessed a factor known as changed-centered leadership.

Anderson (2010) found that public and private managers differ in leadership behavioral styles. Public managers use a change-oriented leadership style. These types of leaders use intuition when making decisions. Private Managers were more relationship oriented which also means that they are power motivated. Hansson (2001) found that nine small businesses in Sweden received an award for implementing TQM which stands for total quality management. The purpose of TQM is "an approach to improve competitiveness, efficiency, and flexibility for a whole organization (Oakland, 1989).

\section{Methods}

Students at universities in India and Sweden were asked to participate in an anonymous voluntary study. They completed the Leadership Orientations (Self) instrument developed by Lee Bolman and Terrance Deal. The data was collected and entered into SPSS for analysis which revealed and then compared the leadership styles and frames Country, Country/Gender, County/Personality Style and Country/ Communication skill level.

\section{Results}

A total of 812 usable surveys were returned with the majority (63\%) coming from Indian students. However, the gender ratio was approximately $60 \%$ females from both groups. Interestingly, approximately $57 \%$ were extroverts from both populations and an overwhelming $87 \%$ of students from both countries self-rated their communication skills as strong or very strong (see Table 1).

Table 1 Demographics

\begin{tabular}{|l|l|c|c|c|c|}
\hline & & & India & Sweden & Total \\
\hline & & $\mathrm{N}$ & 512 & 300 & 812 \\
\hline & & $\%$ & $63 \%$ & $37 \%$ & $100 \%$ \\
\hline Gender & Female & $\mathrm{N}$ & 305 & 169 & 474 \\
\hline & Male & $\mathrm{N}$ & 206 & 130 & 336 \\
\hline & Female \% & $\%$ & $60 \%$ & $56 \%$ & $58 \%$ \\
\hline & Male \% & $\%$ & $40 \%$ & $43 \%$ & $41 \%$ \\
\hline \multirow{2}{*}{ Personality } & Introvert & $\mathrm{N}$ & 225 & 125 & 350 \\
\cline { 2 - 6 } & Extrovert & $\mathrm{N}$ & 287 & 175 & 462 \\
\hline & Introvert \% & $\%$ & $44 \%$ & $42 \%$ & $43 \%$ \\
\hline & Extrovert \% & $\%$ & $56 \%$ & $58 \%$ & $57 \%$ \\
\hline Communication & Weak & $\mathrm{N}$ & 63 & 38 & 101 \\
\hline & Strong & $\mathrm{N}$ & 449 & 261 & 710 \\
\hline & Weak \% & $\%$ & $12 \%$ & $13 \%$ & $12 \%$ \\
\hline & Strong \% & $\%$ & $88 \%$ & $87 \%$ & $88 \%$ \\
\hline
\end{tabular}


The first finding was most students from both countries did not have a distinctive leadership style. Using the Bolman and Deal instrument this "No Style" does not equate to not having any leadership style, but affirms the applicant's responses to the 32-question survey did not achieve the numerical mean of 4.0, the threshold for use of a particular style. While usage of the "Single" "Paired" and Multi style occurred in the 14-19\% range for Indian students and 6-21\% for Swedish students no statistically significant difference by country was found.

When examining the data by gender there were no differences between the females from both countries. However, due to increased use of the paired and multi style by Indian males, a slight but statistically significant difference was found. No significant differences were found based on personality.

The respondents self-rated their communication skills on a Likert like scale. Those who stated they had less than average communication skills were coded as "weak" and those who asserted they had stronger than average communication skills were delineated as "strong". Due to the greater usage of paired and multi style amongst Indian students, a weak but statistically significant difference emerged (see Table 2).

Table 2 Leadership Styles

\begin{tabular}{|c|c|c|c|}
\hline Country & & India & Sweden \\
\hline & Single & $17 \%$ & $21 \%$ \\
\hline & Paired & $14 \%$ & $6 \%$ \\
\hline & Multi & $19 \%$ & $7 \%$ \\
\hline & No Style & $50 \%$ & $66 \%$ \\
\hline & No difference found & & \\
\hline Gender & & India & Sweden \\
\hline \multirow[t]{4}{*}{ Female } & Single & $15 \%$ & $18 \%$ \\
\hline & Paired & $12 \%$ & $7 \%$ \\
\hline & Multi & $19 \%$ & $9 \%$ \\
\hline & No Style & $54 \%$ & $66 \%$ \\
\hline \multirow[t]{5}{*}{ Male } & Single & $20 \%$ & $25 \%$ \\
\hline & Paired & $17 \%$ & $6 \%$ \\
\hline & Multi & $19 \%$ & $3 \%$ \\
\hline & No Style & $44 \%$ & $66 \%$ \\
\hline & $r=.111$, sig .041 & & \\
\hline Personality & & India & Sweden \\
\hline \multirow[t]{4}{*}{ Introvert } & Single & $15 \%$ & $21 \%$ \\
\hline & Paired & $13 \%$ & $5 \%$ \\
\hline & Multi & $18 \%$ & $6 \%$ \\
\hline & No Style & $53 \%$ & $68 \%$ \\
\hline \multirow[t]{5}{*}{ Extrovert } & Single & $18 \%$ & $21 \%$ \\
\hline & Paired & $15 \%$ & $7 \%$ \\
\hline & Multi & $20 \%$ & $7 \%$ \\
\hline & No Style & $47 \%$ & $65 \%$ \\
\hline & No differences by personality & & \\
\hline
\end{tabular}




\begin{tabular}{|c|c|c|c|}
\hline \multicolumn{2}{|c|}{ Communication Skills } & & \\
\hline & & India & Sweden \\
\hline Weak & Single & $8 \%$ & $21 \%$ \\
\hline & Paired & $6 \%$ & $3 \%$ \\
\hline & Multi & $8 \%$ & $11 \%$ \\
\hline Strong & No Style & $78 \%$ & $66 \%$ \\
\hline & Single & $18 \%$ & $21 \%$ \\
\hline & Paired & $15 \%$ & $7 \%$ \\
\hline & Multi & $21 \%$ & $6 \%$ \\
\hline & No Style & $46 \%$ & $66 \%$ \\
\hline & $r=-0.211$, sig .021 & & \\
\hline
\end{tabular}

By comparing the means of the respondents for each frame the relative strength of each can be determined. The frame means could range from a low of 1.0, indicating the participant selected "Never" for each behavior, to a maximum of 5.0 whereby each participant selected "Always" for each behavior. The means for each frame is overall very low which is reflective of most students from both countries admitting to practicing the "No Style" of leadership. A strong statistically significant difference was found at the Human Resources frame as the Indian students employed this frame in far greater frequencies than the Swedish students.

Not surprisingly, when viewing by gender the Indian females used the Human Resource frame .46 of a point by females and .62 of a point by males. Similarly, when viewing by personality type, again the Human Resources frame was used less by the Swedish students. Interestingly, the Swedish Introverts rated their use of the Human Resources frame considerable lower than the Indian students. When analyzing by communication level it was apparent the Indian students who had weaker communication skills showed lower means than their stronger communication counterparts and the Swedish students with weaker communication skills. However, the most noteworthy finding was the extremely low means for the weak communication Indian students with the structural frame (see Table 3).

Table 3 Frame Usage

\begin{tabular}{|l|c|c|c|c|c|}
\hline & India & Sweden & & & \\
\hline Structural & 3.44 & 3.54 & & & \\
\hline Human Resource & 3.58 & 3.06 & $* * *$ & & \\
\hline Political & 3.25 & 3.25 & & & \\
\hline Symbolic & 3.43 & 3.31 & & & \\
\hline & India & & Sweden & & \\
\hline & Female & Male & Female & Male & \\
\hline Structural & 3.44 & 3.43 & 3.56 & 3.53 & \\
\hline Human Resource & 3.53 & 3.66 & 3.07 & 3.04 & $* * *$ \\
\hline Political & 3.20 & 3.33 & 3.26 & 3.24 & \\
\hline Symbolic & 3.40 & 3.46 & 3.33 & 3.28 & \\
\hline & & & & & \\
\hline
\end{tabular}




\begin{tabular}{|c|c|c|c|c|c|}
\hline & India & & Sweden & & \\
\hline & Introvert & Extrovert & Introvert & Extrovert & \\
\hline Structural & 3.36 & 3.50 & 3.53 & 3.56 & \\
\hline Human Resource & 3.47 & 3.67 & 2.97 & 3.12 & $* * *$ \\
\hline Political & 3.26 & 3.24 & 3.21 & 3.28 & \\
\hline \multirow[t]{2}{*}{ Symbolic } & 3.38 & 3.46 & 3.25 & 3.35 & \\
\hline & India & Sweden & India & Sweden & \\
\hline Communication & \multicolumn{4}{|c|}{ Weak Communication Strong Communication } & \\
\hline Structural & 2.81 & 3.42 & 3.52 & 3.56 & $* * *$ \\
\hline Human Resource & 2.82 & 3.03 & 3.69 & 3.06 & \\
\hline Political & 3.13 & 3.09 & 3.27 & 3.28 & \\
\hline Symbolic & 3.20 & 3.19 & 3.46 & 3.33 & \\
\hline $\begin{array}{c}*<.05 \\
* *<.01 \\
* * *<.001\end{array}$ & & & & & \\
\hline
\end{tabular}

The strongest frame for Indian students was the Human Resources frame and the strongest frame for the Swedish students was the Structural frame. The actual means were surprisingly consistent and consequently did not result in statistically significant differences on the variables of gender, personality type, and level of communication skills (see Table 4). The Indian students with the strongest communication skills most frequently employed the Human Resources frame. Conversely, Swedish students with the strongest communication skills most often employed the Structural frame.

Table 4 Strongest Frame

\begin{tabular}{|l|c|c|}
\hline & India & Sweden \\
\hline & Human Resources & Structural \\
\hline Female & 3.58 & 3.54 \\
\hline & Human Resources & Structural \\
\hline Male & 3.53 & 3.56 \\
\hline & Human Resources & Structural \\
\hline Introvert & 3.66 & 3.53 \\
\hline & Human Resources & Structural \\
\hline Extrovert & 3.47 & 3.53 \\
\hline & Human Resources & Structural \\
\hline Weak Communication & Human Resources & Structural \\
\hline & 3.47 & 3.53 \\
\hline Strong Communication & Human Resources & Structural \\
\hline & 3.69 & 3.57 \\
\hline
\end{tabular}


When viewing the weakest frame, it is readily apparent that regardless of the variable of country, gender, personality type, or strong communication skills the weakest frame for Indian students was the Political frame while the Swedish students least favored the Human Resources frame. Interestingly, the means were remarkably consistent across the variables and no statistically significant differences were found (see Table 5). However, the Indian students with weak communication skills least utilized the Structural frame. Not surprisingly, the Introverted Swedish student least employed the Human Resources frame.

Table 5 Weakest Frame

\begin{tabular}{|l|c|c|}
\hline & India & Sweden \\
\hline & Political & Human Resources \\
\hline Female & 3.25 & 3.06 \\
\hline & Political & Human Resources \\
\hline Male & 3.20 & 3.07 \\
\hline & Political & Human Resources \\
\hline Introvert & 3.26 & 3.04 \\
\hline & Political & Human Resources \\
\hline Extrovert & 3.26 & 2.97 \\
\hline & Political & Human Resources \\
\hline Weak Communication & 3.21 & 3.12 \\
\hline & Structural & Human Resources \\
\hline Strong Communication & Political & Human Resources \\
\hline & 3.27 & 3.06 \\
\hline
\end{tabular}

\section{Hypothesis Testing and Implications}

H1: There is no difference in the leadership styles, leadership frames and strongest and weakest frames of university students from India and Sweden. H1 is not supported as there were differences in leadership styles, frame, and strongest and weakest frames between the students from the two countries.

H2: There is no difference in the leadership styles of university students from India and Sweden on the basis of gender, personality type and communication skills.

$\mathrm{H} 2$ is split. It is supported based on personality type. However, H2 is not supported based on gender (males) and communication skills (both strong and weak) displayed as statistically significant differences emerged

H3: There is no difference in the leadership frames of university students from India and Sweden on the basis of gender, personality type and communication skills. H3 is not supported as there were differences in the leadership frames from students of both countries below the .001 level.

H4: There is no difference in the strongest and weakest frames of university students from India and Sweden on the basis of gender, personality type and communication skills. H4 is supported. Even though different frames were used by country, gender, personality type and communication skills no statistically significant differences emerged. 
Despite the disparate differences between the two countries and the homogenous nature of the students, it is apparent these students from various parts of the globe were more alike than different. The high use of the Human Resource Frame by Indian students was consistent with the literature. Culturally, Indian workers seek relationships and nurturing from their employers. These desires were proven in the results of this study. However, the responses of the Swedish students were a surprise as a hallmark of Swedish management is characterized by participative decision making and collaboration. The participants in this study however, eschewed the Human Resource frame.

Perhaps one of the most significant finding of this study is the factor of communication skills. As aforementioned, strong communication skills were a factor in frame usage from both countries. However, regardless of the country, the employment of styles and likewise their frames exhibited lower usage. Similarly, the levels of practice as measured by the frames means were also consistently lower.

As educators it is obligatory for us to assist students in developing their communication ability as it an essential skill for interacting in and dealing with complex environments. Perhaps faculty need to assist this development of these skills in the classroom via experiential learning which could provide experience and allow the students to gain confidence which could help them be better able to use these frames. Some methods for improving oral communications include making oral presentations in front of the class, and adding participation as a component of the assessment. If participation is already a graded factor, perhaps its percentage of the total grade should be increased to show that this classroom behavior is both needed and valued.

Faculty should also consider calling on students when they raise their hands and practice cold calling to challenge them to "think on their feet". This activity serves two purposes as students could develop critical thinking skills as well as improvement of their communication skills.

While it is common for undergraduate students to be shy, it is incumbent on the faculty to give them the opportunity to break out of their shell. Bolman and Deal contend that multi-frame thinking allows for creative solutions which may not have been available when addressing problems from a single frame or perspective. While there are quiet leaders, giving students the chance to show leadership in a safe environment may help them in ways we cannot begin to fathom.

\section{Future Research}

Additional research could focus on the attributes of ethnicity, marital status, grade point average, academic major, and undergraduate versus graduate level. Additional countries could be surveyed as well to ascertain if there are similarities or differences from students from China, Germany, Spain, Brazil and the USA.

\section{References}

1. Andersen, J. A. (2005, December 12-13). The potential of managers to implement change. Paper presented at the 4th Annual International Conference on Leadership Research. Lancaster, UK.

2. Andersen, J. A. (2010). Public versus private managers: How public and private managers differ in leadership behavior. Public Administration Review, 70(1), 131-141. 
3. Bass, B. M. (1990). Bass and Stogdill's handbook of leadership. New York: Academic Press.

4. Bjerke, B. (1999). Business leadership and culture. Cheltenham: Edwards Elgar Publishing.

5. Bloom, N., Genakos, C., Sadun, R., \& Van Reenen, J. (2012). Management practices across firms and countries. Academy of Management Perspectives, 26(1), 12-33.

6. Bogler, R. (2001). The influence of leadership style on teacher job satisfaction. Educational Administration Quarterly, 37(5), 662-683.

7. Bolman, L. G., \& Deal, T. E. (1984). Modern approaches to understanding and managing organizations.

8. Bolman, L. G., \& Deal, T. E. (1991). Leadership and management effectiveness: A multi frame, multi sector analysis. Human Resource Management, 509-534.

9. Bolman, L. G., \& Deal, T. E. (1997). Reframing organizations. San-Franciso: Jossey- Bass.

10. Czarniawska-Joerges, B. (1993). Sweden: A modern project, a postmodern implementation. In D. J. Hickson, Management in Western Europe. Society, culture and organization in twelve nations (pp. 229-247). Berlin: Walter de Gruyter.

11. Desale, P. (2008). Effective leaders are transparent. Silicon india, 38-39.

12. Doh, J. P., Stumpf, S. A., \& Tymon, W. G. (2011). Responsible leadership helps retain talent in India. Journal of Business Ethics, 98(Supplement), 85-100.

13. Edstrom, A., \& Jonnson, S. (1998). Svenskt leaders kap. In B. Czarniawska, Organisations teori pa svenska. Malmo: Liber ekonomi.

14. Ekvall, G., \& Arvonen, J. (1991). Change-centered leadership: An extension of the two-dimensial model. Scandinavian Journal of Management, 7(1), 17-26.

15. Ekvall, G., \& Arvonen, J. (1991). Change-centered leadership: An extension of the two-dimensional model. Scandinavian Journal of Management, 7(1), 17-26.

16. Fleishman, E. A., \& Harris, E. F. (1962). Patterns of leadership behavior related to employee grievances and turnover. Personal Psychology, 15, 43-56.

17. Gerstner, C. H., \& Day, D. V. (1994). Cross-cultural comparison of leadership prototypes. The Leadership Quarterly, 5(2), 121-134.

18. Gonsalves, M., \& Dhende, C. (2015). Nurturant task leadership and work culture in India. DAWN: Journal for Contemporary Research in Management, 2(2), 37-43.

19. Grennes, T. (2003). Scandinavian managers on Scandinavian management. International Journal of Value-Based Management, 16, 9-21.

20. Hampden-Turner, C., \& Trompenaars, A. (1993). Sweden's social individualism: Between raging horses. In The seven cultures of capitalism. Value systems for creating wealth in the United States, Japan, Germany, France, Britain, Sweden, and The Netherlands (pp. 233-260). New York: Doubleday.

21. Hansson, J. (2001). Implementation of total quality management in small organizations: A case study in Sweden. Total Quality Management, 12(7, 8), 988-994.

22. Hansson, P. H., \& Andersen, J. A. (2007). The Swedish principal: Leadership style decision-making style, and motivation profile. International Electronic Journal for Leadership in Learning, 1-13. 
23. Hansson, P., \& Andersen, J. A. (2001). The Swedish Vicar and change. A problematic mismatch. The Journal of Empirical Theology, 12(1), 43-56.

24. Holmberg, I., \& Akerblom, S. (1998). Leadership and culture in Sweden. In Stockholm School of Economics: Centre for Advanced Studies in Leadership Research Paper Series.

25. Holmberg, I., \& Akerblom, S. (2006). Modelling leadership - Implicit leadership theories in Sweden. Scandinavian Journal of Management, 307-329.

26. Jonsson, S. (1995). Goda utsikter. In Svenskt management i perspektiv. Stockholm: Nerenius \& Santerus Forlag.

27. Khetarpal, I., \& Srivastava, R. (2000). Management styles grounded in interpersonal roles: focus on heads of school in India. International Journal of Educational Management, 14(2), 74-83.

28. Lawrence, P., \& Spybey, T. (1986). Management and society in Sweden. London: Routeldge.

29. Lenka, U., \& Tiwari, B. (2016). Achieving triple "P" bottom line through resonant leadership: an Indian perspective. International Journal of Productivity \& Performance Management, 65(5), 694-703.

30. Limbare, S. (2012). Leadership styles \& conflict management styles of executives. Indian Journal of Industrial Relations, 48(1), 172-180.

31. Lindberg, E., \& Vanyushyn, V. (2013). School-based management with or without instructional leadership experience from Sweden. Journal of Education and Learning, 2(3), 39-50.

32. McFadden, C., Miller, B., Sypawka, W., Clay, M., \& Hoover-Plank, S. (2013). Leadership styles and moral judgment competence of community college personnel. Community College Enterprise, 19(2), 63-75.

33. Monahan, M., Shah, A., Bao, Y., \& Rana, J. (2015). Does the field of study influence the choice of leadership? A cross-cultural comparison of business vs. non-business majors. Reseach in Higher Education Journal, 28.

34. Nandamuri, P., \& Rao, K. V. (2011). Leadership and school principals - a study. Asia Pacific Journal of Research in Business Management, 2(12), 1.

35. Palrecha, R., Spangler, W. D., \& Yammarino, F. J. (2012). A comparative study of three leadership approaches in India. The Leadership Quarterly, 23(1), 146162.

36. Pellegrini, E. K., Scandura, T. A., \& Jayaraman, V. (2010). Cross-cultural generalizability of paternalisitc leadership: An expansion of leader-member exhchange theory. Group \& Organization Management, 35(4), 391-420.

37. Rao, M. (2013). Soft leadership style can make you better unit leader. Disability Compliance for Higher Education, 18(11), 8-8.

38. Sapre, P., \& Ranade, M. (2001). Moral leadership in education: an Indian perspective. International Journal of Leadership in Education, 4(4), 367-381.

39. Sharma, S., Sun, H., \& Kannan, S. (2012). A comparative analysis on leadership qualities of school principals in China, Malaysia \& India. International Online Journal of Educational Sciences, 4(3), 1-14.

40. Sinha, J. B. (1978). Superior subordinate relationship and alienation. National Labour Institute Bulletin, 4(3), 209-223.

41. Sinha, J. B. (1980). The nurturant task leader. New Delhi: Concept Publishing House. 
42. Sinha, J. B. (1984). A model of effective leadership styles in India. International Studies of Management and Organization, 14(2/3), 86-98.

43. Sjoborg, E. (1986). Skandinaviskt management. Liber Forlag.

44. Smith, P. B., Andersen, J. A., Ekelund, B., Graversen, G., \& Ropo, A. (2003). In search of Nordic management styles. Scandinavian Journal of Management, 19, 491-507.

45. Sudha, K., Shahnawaz, M., \& Farhat, A. (2016). Leadership styles, leader's effectiveness and well-being: Exploring collective efficacy as a mediator. Vision, 20(2), 111-120.

46. Thompson, M. D. (2000). Gender, Leadership Orientation, and Effectiveness: Testing the Theoretical Models of Bolman \& Deal and Quinn. Sex Roles, 969992.

47. Trompenaars, F. (1995). Riding the waves of culture. London: Nicholas Brealey Publishing.

48. Verma, N., Bhat, A., Rangnekar, S., \& Barua, M. (2015). Association between leadership style and decision making style in Indian organizations. Journal of management Development, 34(3), 246-269.

49. Zander, L., \& Romani, L. (2004). When nationality matters: A study of departmental, hierarchical, professional, gender and age-based employee grouping leadership preferences across 15 countries. International Journal of Cross Cultural Management, 4(3),

\section{About Our Authors}

Amit Shah is Professor of Management at Frostburg State University (FSU) in Maryland. He has over 30 years of experience in industry and academia. Dr. Shah has taught a variety of business courses including business, management, strategic management, and international business. He has presented over 100 papers at various conferences both domestically and internationally, published over 60 refereed articles in various journals and published proceedings, authored/co-authored two texts and conducted workshops for various organizations in the area of business, strategy, and learning. He has received several awards such as Regent's Service Award from University System of Maryland, Frostburg State University's Outstanding Faculty Award in Teaching, Service, and Academic Accomplishment (Research), the FSU College of Business's Outstanding Faculty Research Award, and Outstanding SAM Student Chapter Advisor Award. In 2009, he received the Gold Medal Award in the Global Researcher Category from the Association of Indian Management Scholars (AIMS) International.

Michael Monahan is an Associate Professor and Chair of the Department of Management at Frostburg State University in Maryland. He has 39 years of experience in administration and academia. His primary areas of interest are management, leadership, operations and strategic management. He has published over 40 peer reviewed articles on Entrepreneurship, Leadership, Operations, and has conducted management development workshops for businesses in the community. $\mathrm{He}$ is the advisor for the Frostburg chapter of the Society for the Advancement of Management and has twice been awarded the Advisor of the Year by SAM. He is also active in a number of community organizations. 